\title{
La imagen de América Latina en el diario marroquí Al-
}

\section{Alam:}

\author{
The Image of Latin America in The Moroccan Press
}

\author{
Asesor: Said Benabdelouahed \\ Abdelhak Hiri ${ }^{1}$ \\ hiriest@hotmail.com
}

\section{Resumen}

Este artículo parte de un objeto de estudio muy concreto: conocer cómo se han generado las imágenes de América Latina en el diario marroquí Al-Alam. Dicho de otro modo, estudiar, mediante un análisis de contenidos, cómo está informado el lector marroquí de América Latina y los latinoamericanos por medio de dicha cabecera.

Palabras claves: imagen, América Latina, Al-Alam

\begin{abstract}
This research claims to reveal the image of Latin America in the Moroccan press, specifically in the newspaper Al-Alam. The main purpose of this research is to investigate the associated representation of Latin America of this press by using different methods such as qualitative, thematic, and stylistic. The main objective can be defined as to explain motivations that make the press to lead that representation. The second objective of this study, related to the first, is to study the position of this information. Therefore, during this research analyzing methodology has been used to qualitificate, measure and accomplish by conclusions.
\end{abstract}

Key words: image, Latin America, the Moroccan press

1 Universidad Hassan II, Facultad de Letras y Ciencias Humanas-Casablanca-Ain Chock, Centro de Estudios Doctorales en Ciencias Humanas y Sociales, Formación doctoral: Lenguas y Culturas del Mundo Ibérico e Iberoamericano. 


\section{Introducción}

La imagen de América Latina transmitida por el periódico marroquí Al-Alam es el principal foco de atención de este artículo. Nuestro interés procede de la idea de que los medios de comunicación de prensa ejercen una notable influencia sobre la opinión pública. En este mismo sentido, McCombs señala que: "Los medios informativos no solo determinan en gran medida nuestra concienciación sobre el mundo en general por medio de su entrega de elementos primordiales para elaborar nuestras propias imágenes del mundo, sino que influyen sobre la prominencia de los elementos de esa imagen". ${ }^{2}$ Atendiendo a esta reflexión, podemos inducir que los medios influyen sobre la opinión pública al seleccionar los temas que mejor satisfacen sus intereses. Las grandes cuestiones que se plantean, responden en gran medida a las siguientes preguntas: ¿qué presencia tiene el mundo latinoamericano en el periódico marroquí Al-Alam?; ¿cuál ha sido la evolución histórica de su cobertura mediática?; ¿qué temas relacionados con el mundo latinoamericano predominan en la agenda mediática del diario marroquí?; ¿qué países son mencionados más frecuentemente en la noticias sobre América Latina? Y ¿qué fuentes de información utiliza el periódico para informar sobre América Latina?

Hemos visto oportuno usar una de las herramientas más utilizadas en las ciencias sociales como es el análisis de contenido: "Una técnica de investigación para la descripción sistemática, objetiva y cuantitativa del contenido manifiesto de la comunicación". ${ }^{3}$ El corpus de análisis lo representa el total de noticias publicadas en el diario Al-Alam, durante el período que va del 1 de enero de 1990 a diciembre de 2015.

Al-Alam es un diario marroquí de expresión en árabe, aparece el 11 de septiembre de 1946 y fue fundado por Allal El Fassi. En lo que se refiere a la elección de este rotativo, hay que decir que más que por su ideología (de sensibilidad

2 Maxwell McCombs, "Influencia de las noticias sobre nuestras imágenes del mundo", en Los efectos de los medios de comunicación (investigaciones y teoría), coord. Jennings Bryant y Dolf Zillmann, 13-34 (Barcelona: Paidós, 2003), 17.

3 Bernard Berelson, Content Analysis in Communication Researches (Nueva York: The Free Press, 1952), 18. 
histórica, y por ser mejor organizado.

\section{Análisis de la imagen proyectada por el diario Al-Alam}

En las siguientes páginas, se presentan los resultados obtenidos mediante el estudio de contenido que se realizó de los titulares del diario Al-Alam.

\section{Evolución cronológica de las unidades informativas}

En este capítulo presentaremos los resultados de la evolución de la representación mediática de América Latina en el diario Al-Alam. El siguiente gráfico recoge la distribución de las distintas noticias parecidas en función de su evolución cronológica:

\section{Gráfico 1}

\section{Evolución cronológica de las unidades informativas}

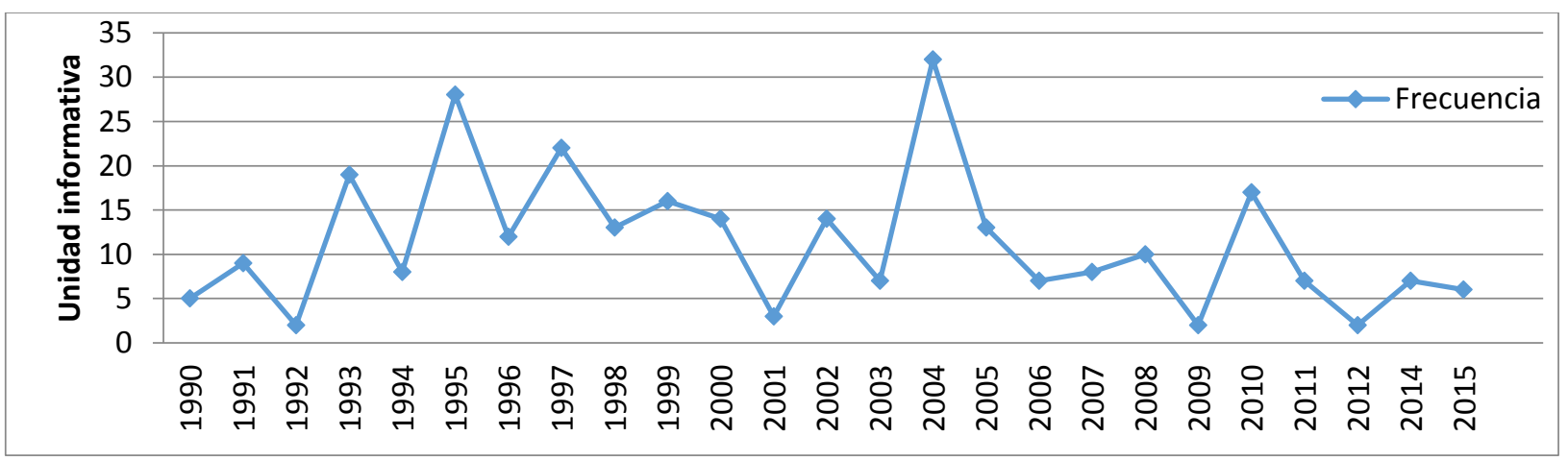

Fuente: Al-Alam. Elaboración propia.

En la actividad de seguimiento realizada durante los 25 años de estudio, hemos podido lograr un total de 283 unidades informativas sobre el tema latinoamericano. Desde un ángulo cuantitativo, la muestra es lo suficientemente representativa para extraer ciertas conclusiones:

Una de las principales observaciones que se impone es la idea de que el periódico Al-Alam, como un periódico marroquí en árabe y de difusión nacional, reserva muy poco espacio periodístico al tema latinoamericano. En otras palabras, el diario objeto de estudio destina una representación periodística notoriamente exigua. 

cobertura a América Latina.

Otro dato de interés es el hecho de que, en el gráfico, se aprecia nítidamente que la distribución de las unidades analizadas por años (283 unidades comunicativas) es notoriamente desequilibrada: hay años en los que se carga la producción informativa y, en cambio, otros años resultan poco noticiosos. Así, podemos observar que, en líneas generales, el año 2004 es más proclive a registrar los máximos de noticias, ya que incluye el $11 \%$ del corpus estudiado. Esta situación se justificaría, sobre todo, porque dicho contexto temporal es cuando se va a producir un notorio acercamiento en la acción exterior de Marruecos hacia América Latina. Se trata de la histórica gira de $\mathrm{Su}$ Majestad el Rey Mohamed VI por los seis países latinoamericanos. Para tener una visión más clara sobre la evolución cronológica de las unidades comunicativas, presentaremos a continuación una visión analítica desde una perspectiva temática.

\section{La agenda temática en las informaciones sobre América Latina}

En este apartado, ofrecemos los resultados vinculados con el análisis de los temas noticiosos sobre América Latina. El siguiente gráfico permite establecer un estudio comparativo entre los diversos temas localizados: 


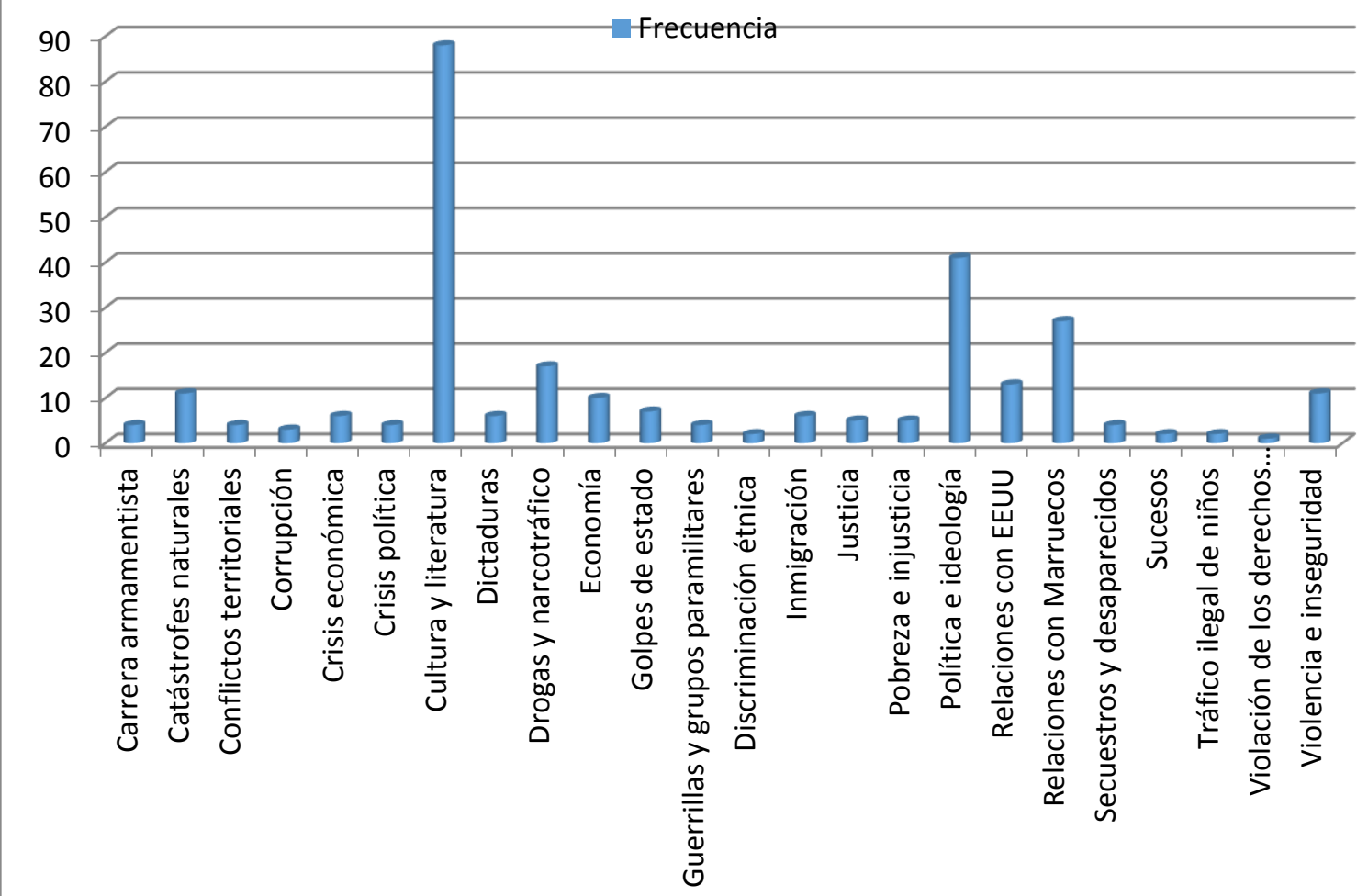

Fuente: Al-Alam. Elaboración propia.

A la vista de los resultados obtenidos en el estudio, se puede observar una gran variedad de temas noticiosos con respecto a América Latina. Se nota asimismo que la agenda temática con respecto a América Latina no resulta más equilibrada.

En efecto, el análisis cuantitativo nos deja ver claramente que el tema con mayor frecuencia es la cultura; este asunto aglutina el 31,09\% del corpus estudiado. La frecuencia refleja claramente el interés prioritario del periódico por dicha temática. En cuanto a la naturaleza, las unidades informativas culturales, conviene matizar que, en su mayoría, informan sobre las grandes figuras y obras del quehacer literario latinoamericano. Podemos ilustrar los siguientes ejemplos que evidencian este hallazgo: "Qirā‘āat fi ādab āmrika āl-ŷanubiya āl-mu ās” (transcirpción latina), "Características de la literatura latinoamericana contemporánea" (traducción nuestra) Al-Alam, 19 de octubre de 2004, última página;. "Tadā iyāt $\bar{u}$ ctabīū bāz harā'ib gāltā āl-mūallaqah" (transcripción latina), "Octavio Paz: La ruinas colgadas de Galta" (traducción nuestra), Al-Alam, 1 de noviembre de 1991, última página; "Gābriyil Gārcyá Márkiz țā'irat āl-ŷamila ārrāqida” (transcripción latina), "Gabriel García Márquez: El avión de la bella durmiente" (traducción nuestra), Al-Alam, 10 de diciembre de 1997, p. 7. 
Por su parte, el análisis temático revela la presencia de algunas piezas comunicativas culturales referidas a la contribución de los árabes en la cultura latinoamericana. Veamos el siguiente titular: "Al-mūslimūn fi ŷūzūri āl-kāribi" (transcripción latina), "La comunidad musulmana en el Caribe" (traducción nuestra), Al-Alam, 26 de mayo de 1991, p. 3. Además, el diario objeto de estudio presenta a sus lectores una sinopsis de una película que recibe el título Diarios de motocicleta. Esta pieza comunicativa resalta una parte muy significativa de la historia latinoamericana. Se trata del diario que redactó Ernesto Guevara en diciembre de 1951, a la edad de 23 años cuando decidió emprender un largo recorrido en moto por América Latina con su amigo Alberto Granada. Veamos el siguiente titular "Yawmiyāt $\bar{u}$ darāŷah nāriyah fi āmrikā āllātiniyah” (transcripción latina), "Diarios de motocicleta, notas de viaje por América Latina (Ernesto "Che" Guevara)" (traducción nuestra), Al-Alam, 28 de octubre de 2006, p. 6.

Por su parte, el tema de las relaciones de América Latina con Marruecos ocupa el segundo puesto en la escala de los temas más noticiosos. En concreto, incluye un total de 77 unidades comunicativas, o sea, el 27,20\% del corpus hace una referencia explícita a este aspecto temático. Desde una perspectiva crono-temática, hemos constatado un mayor interés informativo del diario Al-Alam por las dinámicas diplomáticas recíprocas que tuvieron lugar en el año 2004. En concreto, la visita que Su Majestad el Rey Mohamed VI efectuó a América Latina en 2004 recibió un particular eco mediático. Podemos citar el siguiente ejemplo: "ŷalālalū āl-malik yabda' $\bar{u}$ ŷawlatah $\bar{u} f i$ āmrikā āllātiniyah biziyārati āl-miksik” (transcripción latina), . “Su Majestad Rey inicia su gira por América Latina con su vista a México" (traducción nuestra), Al-Alam, 24 de noviembre de 2004, p. 1.

Por su parte, el tema de la cuestión del Sahara marroquí recibió una posición privilegiada en la agenda mediática del órgano periodístico estudiado. Veamos el siguiente titular: "bārāgwāy tashabū i tirafaha bi āl-ŷūmhūriya āssahrāwiya ālmaz ūma" (transcripción latina), "Paraguay retira su reconocimiento de la pseudoRASD” (traducción nuestra), Al-Alam, 1 de mayo de 2014, p. 1.

El tercer puesto en la escala de los resultados, encontramos el tema político, que aglutina el 6,71\% del corpus estudiado. En cuanto a la naturaleza de este asunto, destacamos que el diario objeto de estudio hizo una especial cobertura a algunos 
aspectos relativos a los grandes cambios políticos que definen el mapa político latinoamericano. La siguiente unidad informativa argumenta este hallazgo: "Āddimūqrātiyah bi āshili maqrūnah bi islāhi āddūstūri" (transcripción latina), "La democracia en Chile ligada a las reformas de la Constitución" (traducción nuestra). Al-Alam, 26 de marzo de 2000, p. 5.

Siguiendo con el análisis temático, el diario objeto de estudio comparte con sus lectores la historia de una de las figuras más simbólicas del espacio latinoamericano. Se trata del ideólogo y comandante Che Guevara. Veamos el siguiente titular: "Āssana ālgāmida min hayāt ātta'ir ālkūbi, Âsrār min ḥayāt shi Gifārā fi 1-awhal āl-ifrikiyā” (transcripción latina), "La vida misteriosa del rebelde cubano, algunos secretos de la vida de Che Guevara en África (traducción nuestra)", Al-Alam, 3 de marzo de 1995, p. 3.

El cuarto puesto lo ocupa el tema de las drogas y el narcotráfico; este asunto abarca un total del $6 \%$ del corpus analizado. Ilustramos el ejemplo del siguiente titular: "Mūhaddirāt: hal tūsbihū āl- miksik kūlūmbyā tāniyah" (transcripción latina), "Narcotráfico, ¿puede convertir a México a una Colombia?" (traducción nuestra), AlAlam, 12 de junio de 1993, 4. Desde nuestra perspectiva, esta situación, de alguna manera, refuerza el carácter prejuicioso de algunos países latinoamericanos.

Le sigue en importancia de frecuencia, el tema del intervencionismo estadounidense en el subcontinente latinoamericano. El siguiente titular ejemplifica este aspecto temático: "Hāyti wa kūbā shawkatān fi hạlqi āmrikā" (transcripción latina), "Haití y Cuba, grandes enemigos de EE. UU." (traducción nuestra), Al-Alam, 1 de enero de 1995, p. 2.

Por su parte, el tema de las catástrofes naturales acapara el $11 \%$ de las unidades comunicativas analizadas. En esta misma línea, apreciamos un tratamiento periodístico dosificado de noticias relativas a este asunto. Podemos ilustrar el ejemplo del siguiente titular: "Hāzzā ārdiyah qawiyāh tadribū shamāla garbi āl-ikwadūr" (transcripción latina), "Un fuerte seísmo sacude el noroeste de Ecuador" (Traducción nuestra), AlAlam, 22 de marzo de 1992. p. 5.

Llama la atención que el tema económico figura entre las dimensiones menos informadas; este aspecto temático tiene apenas el 3,53\% del corpus estudiado. Este hecho demuestra el desinterés mediático del periódico por las cuestiones económicas latinoamericanas. Entre las pocas unidades informativas que informan sobre este 

sāsatihā wa-ṣūndūqi ānnaqdi āddawliyi”" (transcripción latina), “Argentina, víctima de sus políticos y el Fondo Monetario Internacional" (traducción nuestra), Al-Alam, 13 de enero de 2002, p. 5.

En definitiva, los resultados que se ofrecen son muy relevantes; evidencian que la agenda temática del diario Al-Alam gira en torno a temáticas preferentemente culturales y, en menor medida, políticas o económicas, donde llama poderosamente la atención el tratamiento positivo que se da a las noticias sobre América Latina y los latinoamericanos. Si bien es cierto que siguen algunos aspectos negativos, sobre todo en cuestiones de narcotráfico e inseguridad ciudadana, estas imágenes pierden mucha presencia informativa a favor de asuntos culturales.

\section{Los géneros periodísticos utilizados}

En este capítulo, estudiaremos los diferentes géneros periodísticos con los que trabaja el diario Al-Alam el tema latinoamericano. El siguiente gráfico recoge la distribución porcentual de las unidades comunicativas según el género periodístico:

Gráfico 3

Distribución porcentual de los géneros periodísticos

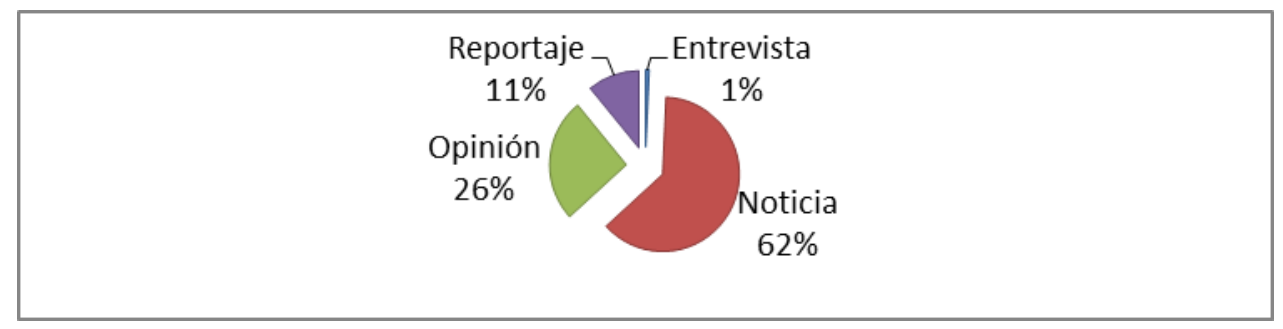

Fuente: Al-Alam. Elaboración propia.

Al tenor de los resultados obtenidos, podemos observar que la noticia es, sin lugar a dudas, el género predominante. En concreto, un total de 177 unidades informativas (62\%), se encajan con este tipo de texto. Con respecto a la naturaleza de estas piezas, hay que señalar que, en su mayoría, son noticias que surgen de diferentes agencias informativas internacionales. El segundo puesto, lo ocupa el género opinión, que incluye un total de 73 unidades (el $26 \%$ ) que se corresponden a este tipo de género. Con respecto a las informaciones que se publican con este estilo, destacamos que suelen relacionarse con ciertos temas de críticas literarias que precisan de un 

distancia aparecen el resto de variables. Así, vemos que se han registrado 31 reportajes, o sea el $11 \%$ del corpus estudiado. Por último, la entrevista figura en la última escala de los resultados, que incluye tan solo el $1 \%$ de la muestra.

Los datos revelan que el diario Al-Alam se limita a relatar exclusivamente los hechos. Esto nos permite deducir que el órgano periodístico objeto de estudio no hizo una cobertura en profundidad del acontecer latinoamericano. A nuestro entender, sería pertinente inculcar otros géneros periodísticos cómo la crónica, la opinión y las entrevistas. Todo ello le daría riqueza y cercanía con las informaciones latinoamericanas.

\section{Origen geográfico de la información}

El estudio permite establecer un análisis comparativo de la presencia informativa de los diferentes países que conforman el mapa latinoamericano. El siguiente gráfico permite ver la distribución por países de las 283 piezas identificadas en la muestra de 25 años de estudio:

Gráfico 5

Distribución de las unidades por países

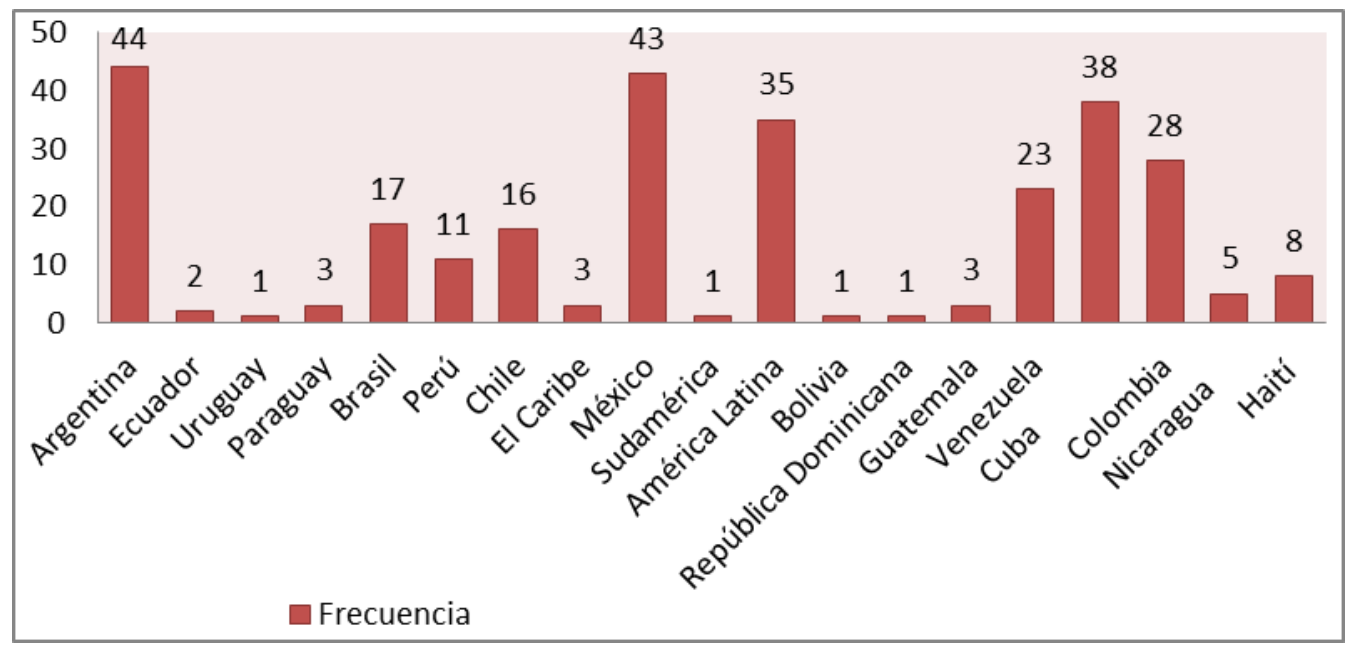

Fuente: Al-Alam. Elaboración propia.

A la vista del gráfico, se puede observar una clara discriminación informativa entre los diferentes países latinoamericanos. Esto es: no todos los países son 
representados por igual ni en cantidad ni calidad; hay países en los que se carga la producción informativa y, en cambio, otros resultan desiertos mediáticos por no encontrar información sobre ellos.

Los países protagonistas de las unidades informativas analizadas son Argentina, México y Cuba. El primer país que aparece como origen de información latinoamericana es Argentina. Es origen de un número muy elevado de informaciones, con un total de 44 unidades comunicativas, lo que representa algo más del $15 \%$ de la información estudiada. El segundo país con mayores valores informativos es México; ha generado un total 43 unidades informativas, o sea, el 15,19\% del corpus estudiado.

Por su parte, Cuba recibe una posición privilegiada en las páginas del diario objeto de estudio. En este sentido, destacamos que este país caribeño ocupó el tercer país en la escala de los resultados. Con respecto a la naturaleza de las piezas que se publican sobre dicho país, hay que destacar la presencia de varias unidades informativas que critican la penosa situación de los niños saharauis en Cuba. Dicho de otro modo, el diario objeto de estudio pone mucho énfasis sobre la postura del país caribeño con respecto al Sahara marroquí. Veamos el siguiente titular: “Ál-būlizāryū yūshagil āl-atfāl āssahrawiyin fi ādda âra fi Kūba", "El Polisario prostituye a niños saharauis en Cuba" (traducción nuestra) (transcripción latina), Al-Alam, 16 de marzo de 2002, 5 .

Por su parte, América Latina recibe un emplazamiento más acomodado en la agenda informativa del periódico estudiado. Hemos localizado un total de 35 piezas informativas en las que el nombre de América Latina aparece en el titular, lo que supone el $12 \%$ del corpus estudiado. Este hecho demuestra que el diario marroquí entiende a los países latinoamericanos como algo común, como un todo comunicativamente, como un fenómeno informativo integrado.

El quinto país es Colombia; incluye un total de 28 unidades comunicativas, lo que representa el 9,85\% del corpus estudiado. Luego, en su orden, aparecen los siguientes países: Venezuela, 23 unidades comunicativas; Brasil, 17; Chile, 16; Haití, 8; y, Nicaragua, 5.

En el extremo opuesto hay varios países que han mostrado una muy frágil referencialidad informativa, tales los casos de Paraguay y Guatemala, que absorben apenas tres unidades comunicativas respectivamente; y Ecuador, dos piezas informativas. Llama poderosamente la atención que de varios países, sobre todo centroamericanos, no se muestra ninguna referencia informativa. En este sentido, 
prácticamente inexistentes e invisibles en la agenda informativa del diario objeto de estudio. Este hecho, nos permite afirmar que dichos países no constituyen para el diario marroquí una fuente informativa de importancia.

Con respecto a las agendas temáticas y análisis de las diferencias entre países, observamos que existe una relación entre el espacio dedicado a cada país y la temática en la que se enmarca. Así, la cobertura informativa de Argentina en el periódico AlAlam, durante el espacio temporal estudiado, estuvo centrada principalmente en dos dimensiones: la cultura y las relaciones económico-políticas con Marruecos. De hecho, podemos hablar de una valoración positiva de este país sudamericano.

En relación con la representación mediática de México, hemos constatado que el análisis del conjunto de informaciones revela que fueron más favorables que desfavorables. En este mismo sentido, destacamos que la representación de este país centroamericano fue positiva dando una imagen pública de país de gran riqueza literaria. El diario objeto de estudio hizo una especial referencia informativa a las grandes figuras del quehacer literario mexicano, tales como Leopoldo Cea, Carlos Fuentes y Octavio Paz.

Contrariamente a la representación informativa de dichos países, el diario $A l$ Alam hizo una atención noticiosa a Cuba fuertemente negativa. La cobertura informativa de este país caribeño estuvo marcada por temáticas políticas pésimas; es retratado como un país con fuerte actitud adversa hacia la integridad territorial marroquí, especialmente en lo relativo al tema del Sahara marroquí. Prueba de ello, como anticipábamos, la idea de que muchas de las unidades comunicativas denuncian el tema de los maltratos a niños saharauis en Cuba.

\section{Las fuentes de información localizadas}

Para comprender mejor el tratamiento informativo del periódico Al-Alam con América Latina, es preciso indagar las fuentes de información como un factor generador de las noticias. Respecto al corpus informativo que hemos analizado, en este gráfico, se da a conocer la distribución de las fuentes de información: 
Distribución de las fuentes localizadas

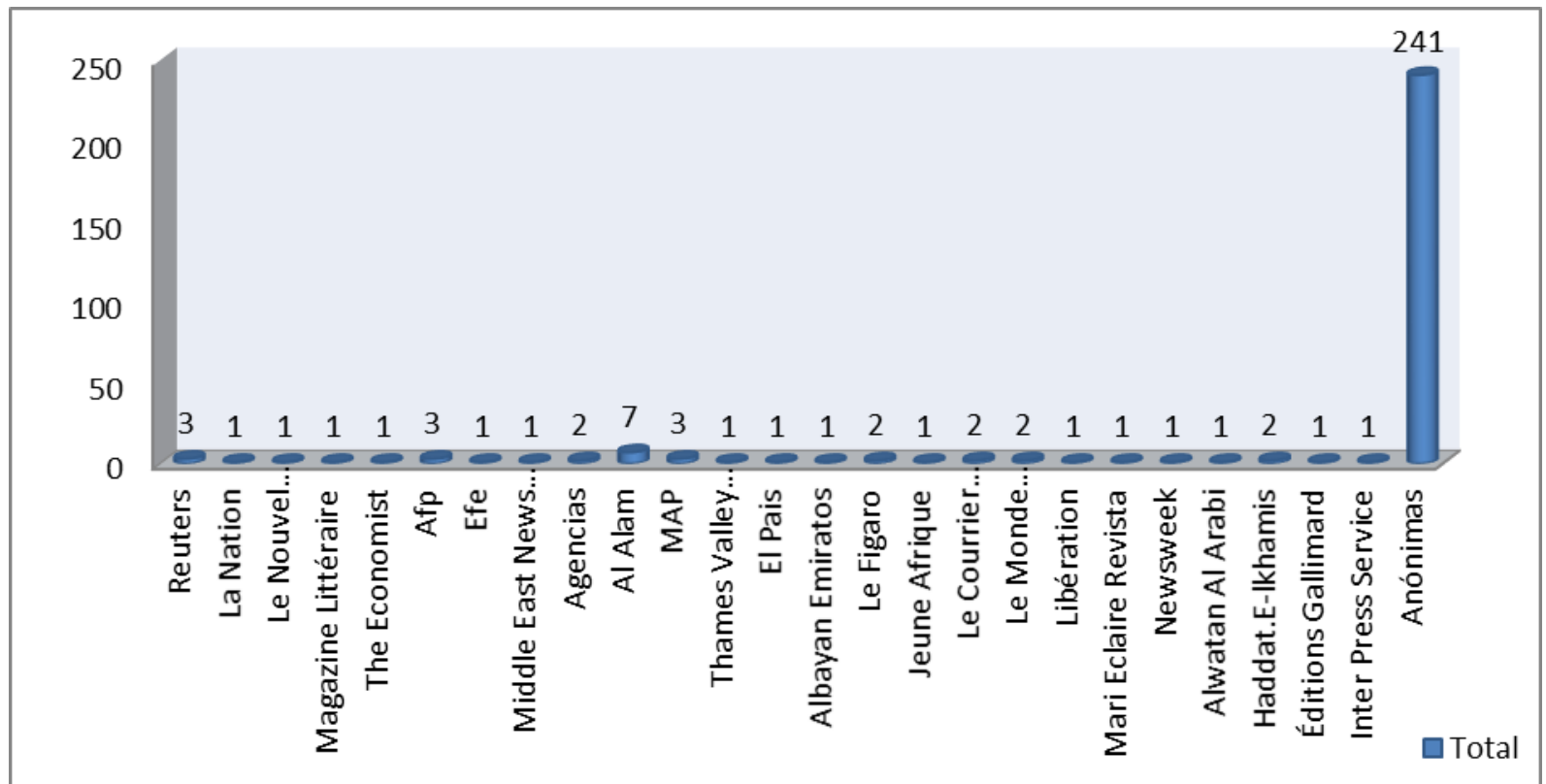

Fuente: Al-Alam. Elaboración propia.

La representación gráfica de las fuentes informativas evidencia el peso del anonimato; se percibe un amplio número de noticias que surgen de fuentes totalmente desconocidas. Así, de las 283 unidades comunicativas, 241 no se da a conocer la fuente informativa, o sea, el 85,15\% de las noticias identificadas no poseen fuentes.

Por su parte, el análisis cuantitativo revela una notoria presencia de unidades informativas firmadas por grandes órganos periodísticos europeos y un predominio algo desconcertante de sus propias redacciones. Esta situación permite desvelar que el periódico objeto de estudio no disponía de una corresponsalía o una delegación de prensa; de hecho, se abastecía de los servicios de las agencias para poder obtener la información del suceso de manera rápida y precisa.

Así, hemos encontrado muchas veces referencias a prestigiosas voces periodísticas francesas. Estas referencias a veces eran explícitas, como las hechas a los siguientes periódicos: Le Monde Diplomatique; Le Courrier International; La Nation; La Nouvel Observation; Magazine Littéraire; Le Figaro; Jeune Afrique; Libération; Éditions Gallimard y; la revista Mari Eclaire. Estos medios representan el 5,65\% del corpus estudiado. Por tanto, las fuentes informativas francesas son las más usadas por el periódico Al-Alam por ser las más accesibles. 
Aparte de las referencias francesas, también se han encontrado referencias a otras agencias de noticias europeas como la agencia británica Reuters que se presenta en el 1,06\% de las noticias analizadas, y que supera a la francesa AFP que subre el 0,1\% de cuota entre estas grandes empresas informativas.

Además de la agencia Reuters, el diario objeto de estudio se aprovisiona de otro medio británico, la publicación semanal en inglés The Economist. Se constata asimismo una publicación informativa que surge de la universidad inglesa Thames Valley University. Estos datos demuestran que el diario objeto de estudio se abastece también de fuentes informativas británicas para las información latinoamericana.

Por su parte, la agencia española EFE figura en los últimos puestos como punto de aprovisionamiento de información latinoamericana. Su presencia se hizo sentir solamente en una unidad informativa.

Siguiendo con el análisis de las fuentes, vemos que solo en siete ocasiones las informaciones publicadas aparecen firmadas por el propio periódico, lo que representa el 2,47\% del conjunto de las fuentes informativas identificadas.

Finalmente, una de las particularidades peculiares que identifica Al-Alam en relación con su cobertura mediática del espacio latinoamericano es la presencia de algunas fuentes informativas árabes. En esta misma línea, destacamos la presencia de la agencia egipcia MENA (Middle East News Agency). También constatamos otras dos prestigiosas revistas del golfo arábigo: Albayan de Emiratos y Alwatan Al-Arabe que generaron dos unidades comunicativas respectivamente.

Así, parece que el periódico Al-Alam recurre constantemente al uso de agencias internacionales; es la tendencia dominante del diario marroquí objeto de estudio. En otras palabras, una serie de países europeos controlan la mayor parte de las informaciones sobre el mundo latinoamericano. Se percibe que países como Francia y Reino Unido han podido generar más información latinoamericana que las propias fuentes nacionales marroquíes.

La preponderancia de las fuentes de origen europeo sobre las de países latinoamericanas o nacionales marroquíes, permite revelar cómo dichas fuentes monopolizan la información del mundo latinoamericano. En otros términos, el diario Al-Alam reproduce la visión informativa y la imagen que dichos medios europeos construyen de América Latina. En cambio, las voces de marroquíes son casi inexistentes, lo que demuestra la teoría de la dependencia de las agencias de 
información. Este hecho se refuerza tomando en consideración la idea de que la agencia marroquí Maghreb Arabe Presse (MAP) ha podido generar apenas unas tres tímidas noticias relativas al espacio latinoamericano.

\section{Autores de las unidades comunicativas}

En este campo, se presenta la naturaleza de las personas que hicieron responsables de las unidades informativas. La siguiente gráfica da a conocer la nacionalidad de los autores:

\section{Gráfico 7}

Distribución porcentual de los autores por nacionalidad

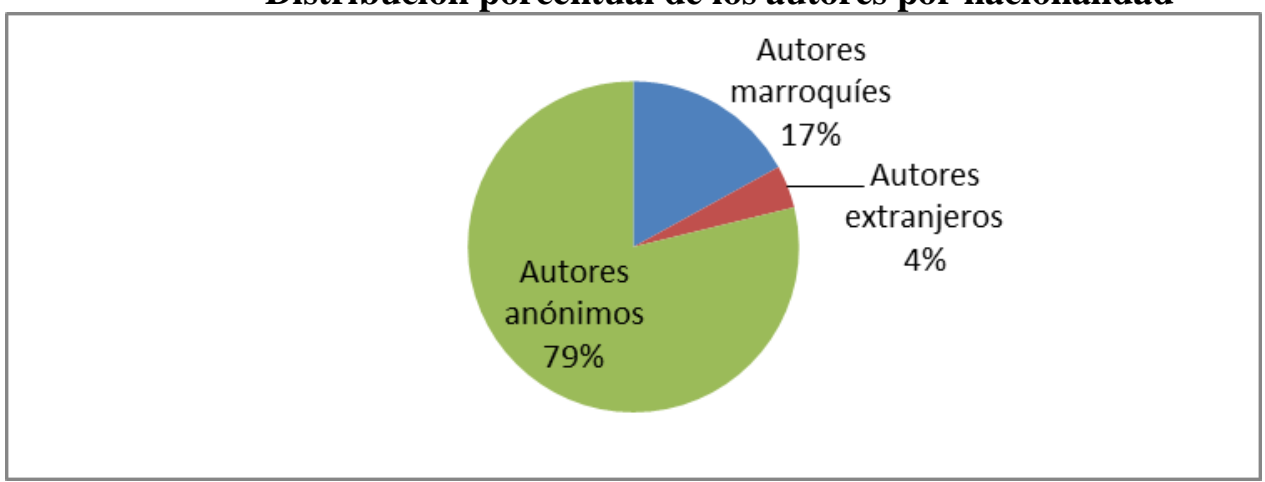

Fuente y elaboración propias.

Como podemos ver en el gráfico, de las 283 unidades informativas seleccionadas entre 1990 y 2015, 217 aparecen sin firma. Por tanto, la tendencia general es el predominio del anonimato. Otra de las observaciones que se imponen es la idea de que hemos podido constatar una ausencia declarada de corresponsales marroquíes en las tierras latinoamericanas.

En lo tocante a la nacionalidad de personas identificadas como redactores de las piezas periodísticas, hemos podido comprobar que la mayoría de cantidad de autores son marroquíes. Sobre la naturaleza de estos últimos, hay que destacar que, en general, hubo colaboradores que mostraron tener un notorio talento periodístico de reconocido prestigio. Podemos ilustrar el ejemplo del prestigioso periodista, exembajador marroquí en Brasil y exministro de Comunicación marroquí, Mohamed Larbi Messari; este autor es considerado uno de los mejores conocedores marroquíes 
del tema latinoamericano. Este autor ha firmado, durante el espacio temporal estudiado, un total de cinco unidades informativas. Junto a este autor, podemos citar al exdiplomático marroquí Mohamed Mohamed El-Khattabi, que expone sus reflexiones acerca el quehacer literario latinoamericano. En concreto, ElKhattabi ha firmado 11 unidades informativas, en las que expresa sus impresiones sobre las figuras más representativas de la literatura latinoamericana: Gabriel García Márquez, Carlos Fuentes, Juan Rulfo, José Emilio Pacheco y la poetisa, traductora literaria y ensayista mexicana Elsa Cross.

Por lo demás, hemos percibido, aunque en menor medida, una cantidad significativa de autores que figuran como traductores de grandes obras literarias latinoamericanas. Podemos mencionar algunos ejemplos como: Rachid Ouhatta, quien fue responsable de varias traducciones literarias del inglés al árabe. También podemos citar las traducciones de los autores Abderrahim Hazal y Abdessalam Ettaouil, que aparecen como traductores al árabe de las obras literarias del escritor Jorge Luis Borges.

Es importante destacar que, gracias a estos autores, los lectores del periódico Al-Alam, tenían más posibilidad de percibir al subcontinente latinoamericano como un espacio geográfico de gran riqueza literaria.

\section{Número de las páginas (la estructura para-textual)}

En este apartado, tratamos de medir, mediante el número de página donde se localiza la información, la importancia que el periódico Al-Alam da a la información sobre América Latina. El siguiente gráfico recoge el número de la página en el que se insertan las unidades comunicativas:

Gráfico 8

Distribución porcentual de las páginas

Más de diez páginas

Fuente: Al-Alam. Elaboración propia. 
A la vista de la gráfica, se aprecia que, de las 283 noticias analizadas, solo 24 noticias $(9 \%)$ de los ejemplares analizados se destacan ubicadas en la Portada. Este dato permite constatar que América Latina no constituye una prioridad informativa para el diario marroquí objeto de estudio. En otros términos, las informaciones sobre América Latina en el periódico analizado no son consideradas como noticias relevantes desde el punto de vista informativo.

Por su parte, las páginas tres, cuatro y cinco acaparan la mayor cantidad de unidades comunicativas, principalmente porque corresponden a la sesión especial de asuntos internacionales. La Contraportada ha ganado un peso significativo en el tratamiento informativo sobre el espacio latinoamericano. Así, hemos percibido un 20 $\%$ de las unidades localizadas que se insertan en la Última Página.

\section{Extensión de la unidad de análisis (el espacio)}

En este campo, tratamos de realizar una descripción física de las unidades informativas localizadas. La siguiente gráfica presenta el espacio que ocupan las piezas comunicativas localizadas:

\section{Gráfico 10}

Distribución porcentual del espacio asignado a las piezas comunicativas

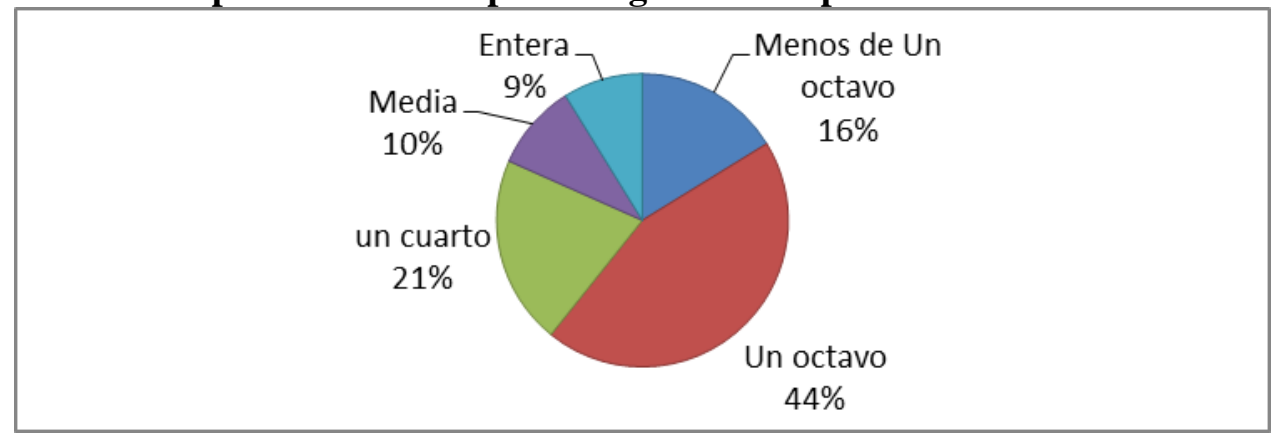

Fuente: Al-Alam. Elaboración propia.

Como podemos ver, la gran mayoría de las unidades de análisis presentan una extensión inferior a un cuarto de página; en concreto, un $21 \%$, ocupa menos de un cuarto de página y, un total de $48 \%$ se extienden a un octavo de la misma. A continuación, se puede observar que apenas el $10 \%$ de ellas se publican en una media 
página. De forma similar, solo el $9 \%$ de las noticias analizadas, se publican a toda página.

En definitiva, los resultados del estudio ponen de manifiesto que la información sobre América Latina o latinoamericanos ocupa un lugar menor o poco destacado en el periódico objeto de estudio.

\section{Conclusiones}

Del análisis de la producción informativa del periódico Al-Alam, se pueden señalar algunas consideraciones generales:

Desde el punto de vista cuantitativo, destacamos la escasez de información latinoamericana. La adscripción temática de los hechos seleccionados refuerza una visión de América Latina, generalmente favorable. Dicho de otro modo, el tratamiento de América Latina en el diario objeto de estudio estuvo dominado por una visión positiva: la mayor parte de las notas de prensa durante los años 1990-2015 recogieron actividades relacionadas con la cultura y la literatura.

El enfoque geográfico predominante en las informaciones que se publican el periódico Al-Alam evidencia una vinculación relativa entre el enfoque geográfico predominante y los países hacia donde cada país destina prioritariamente sus relaciones internacionales. Así, hemos constatado que existe un claro protagonismo de Argentina, México y Cuba; el 87,7 \% de las informaciones analizadas tenía como protagonista a uno de estos países.

Otro detalle que no debe pasar desapercibido, es el hecho de que la información relativa al espacio latinoamericano es relatada desde fuentes extranjeras. En cuanto a los géneros periodísticos utilizados, la información es, sin lugar a dudas, el género predominante. Junto a ello, podemos destacar que el mayor peso de las noticias o unidades periodísticas sobre América Latina se registra en la sección de información internacional.

En síntesis, la percepción revelada es que de América Latina se habla poco y con una cierta preponderancia de temas literarios. 


\section{Bibliografía}

Berelson, Bernard. Content Analysis in Communication Researches. Nueva York: The Free Press, 1952.

McCombs, Maxwell. "Influencia de las noticias sobre nuestras imágenes del mundo". En Los efectos de los medios de comunicación (investigaciones y teoría), coordinado por Jennings Bryant y Dolf Zillmann, 13-34. Barcelona: Paidós, 2003. 